\title{
Shutdown hits health services, but Obamacare steams on
}

$\mathrm{T}$

he political paralysis that has closed much of the United

States government is delivering a blow to medical research, dampening disease detection and keeping the gravely ill out of potentially life-saving clinical trials. What it's not doing is slowing the march of Obamacare, the sweeping health care law Republicans are trying to stop any way they can.

The first government shutdown since the winter of 1995-96 has idled some 800000 federal employees and curbed services across the breadth of government. Republicans in control of the House of Representatives are demanding that the health care law, nicknamed Obamacare, be scaled back as a condition of financing the rest of government. President Barack Obama and his fellow Democrats who control the Senate say "No" to that.

The budget deadlock has little effect on the law expanding health insurance to most of the uninsured because its core elements are an "entitlement," like Social Security pensions, with a completely separate money stream that does not require an injection of appropriations by Congress each year.

It's a different story for the National Institutes of Health (NIH), the US Centers for Disease Control and Prevention (CDC), the US Food and Drug Administration (FDA) and many other parts of government that have been forced to abandon all but their most urgent tasks.

At the NIH Clinical Center in Bethesda, Maryland, no new patients will be admitted into clinical trials, officials said. That means the centre will turn away an estimated 200 people a week, including 30 children, most with cancer. Other crimps in NIH operations have international ramifications. New research-grant applications are being set aside and PubMed, the vast online repository of medical information, is limping along with a skeletal staff.

It's looking grim, too, at the CDC, where only one-third of the staff is still at work. Among the consequences: reduced monitoring of emerging contagions and new forms of avian flu, no more tracking of seasonal flu and a stop to lab work that is key to detecting future outbreaks.

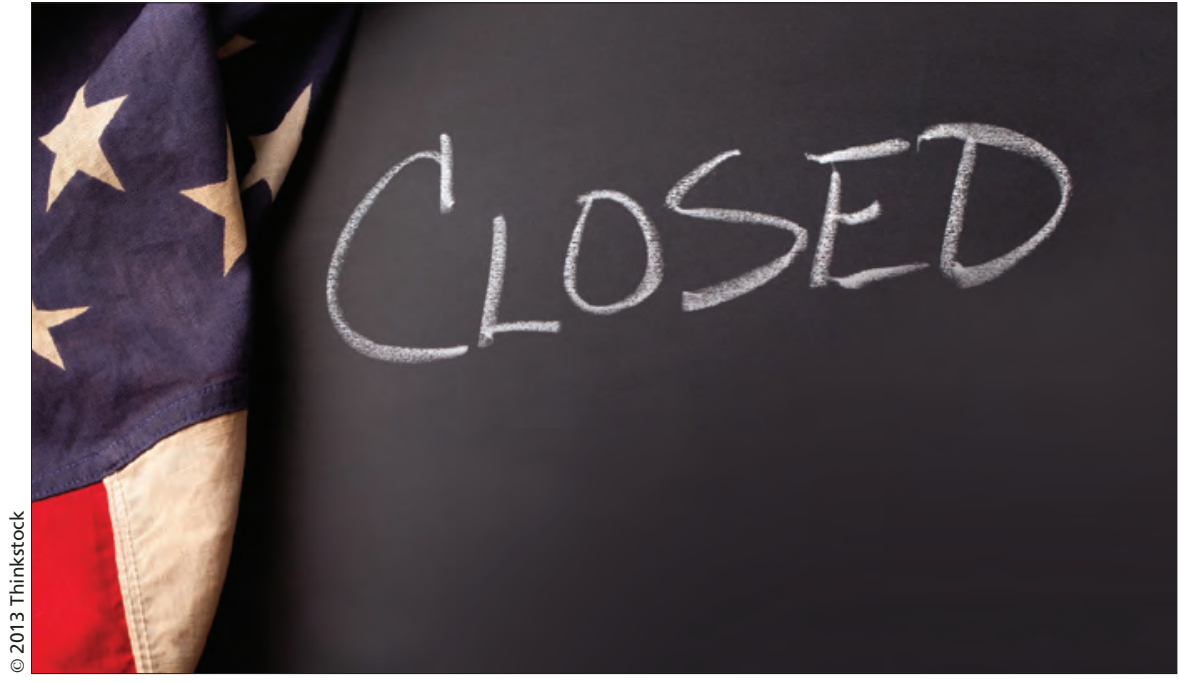

The first US government shutdown since 1995-96 has idled federal employees and curbed services across the government, including health services and research.

"This shutdown is about rolling back our efforts to provide health insurance to folks who don't have it," Obama said as government offices emptied. "One faction, of one party, in one house of Congress, in one branch of government, shut down major parts of the government all because they didn't like one law."

A day after the shutdown began, House Republicans passed legislation to restore NIH financing and some other federal enterprises snagged in the dispute, but Democrats said their opponents should join them in reopening the government entirely and forget about cherry-picking what they like.

Day one of the shutdown oddly coincided with the biggest day yet for Obamacare since its enactment more than three years ago. New health insurance markets established under the law debuted online and began accepting customers for coverage that begins in January.

But the rollout wasn't pretty. The markets, called exchanges, were overwhelmed by nearly 5 million unique visitors to a gateway website, as well as 190000 phone inquiries to a call centre. That left hordes of people frustrated and apparently few actually served.

Obamacare has yet to overcome the public's suspicion that the overarching promise of affordable medical care for all might turn out to be so much hot air. Polls find, though, that the general pub- lic is not clamouring to have it repealed.

Instead, the clamour comes from a cadre of conservatives in Washington, DC, supported by the politically energized Tea Party movement, who won't back down in trying to kill the law even when that means shuttering government.

"What this is, really, is kind of a hostage-taking," says Calvin Mackenzie, a professor of government at Colby College in Waterville, Maine.

"Today Obamacare is the surrogate for big government, and instead of saying, 'We're against big government,' they're saying, 'We're against Obamacare."”

The contingency plan now in effect for federal health services spells out which functions are derailed and which go on. The disruption is substantial.

At the FDA, routine food safety inspections are stopping along with most of the agency's activities with nutrition and cosmetics. Meat will continue to be inspected by the Agriculture Department.

You could say that America's most majestic mental health program has also gone down the tubes. From the Grand Canyon in the southwest to coastal Maine, the national parks, those restorative places of peace and quiet far from the recriminations flying in Washington, are all closed. - Cal Woodward, Washington, DC

CMAJ 2013. DOI:10.1503/cmaj.109-4623 